\title{
Socio-Culturalism and Knowledge Sharing in Multicultural Virtual Learning Communities: Mapping a Conceptual Framework using a Case-based ‘Quanto-Phenomenography’ Approach
}

\author{
Farooq Mughal (Corresponding author) \\ Department of Management Sciences, \\ COMSATS Institute of Information Technology (CIIT) \\ Park Road, Chak Shehzad, Islamabad - 44000 Pakistan \\ Tel: 0092-336-5232053 E-mail: farooq_mughal@comsats.edu.pk
}

Aneesa Zafar

Department of Management Sciences,

COMSATS Institute of Information Technology (CIIT)

Park Road, Chak Shehzad, Islamabad - 44000 Pakistan

Tel: 0092-333-5625633 E-mail: aneesa_zafar@comsats.edu.pk

Accepted: November 2, $2011 \quad$ Published: December 13, 2011

Doi:10.5296/ijld.v1i2.1178 URL: http://dx.doi.org/10.5296/ijld.v1i2.1178

\begin{abstract}
The aim of this paper is to investigate the impact of socio-cultural values on the process of knowledge sharing in a multicultural virtual (online) learning community. The study was conducted on a community of place consisting of a mix of students $(n=50)$ from different parts of the world using a virtual learning environment designed to support learning within and outside the classroom. Pertinent to this, the paper explores three significant areas: a). what societal and cultural values influence the process of knowledge sharing; $b$ ) which values are considered important by the community members; and c). do these socio-cultural values limit the utility of a virtual learning environment. The theoretical basis of this study is strongly related to Vygotsky's (1983) theory of 'mediated mind' and Thorne's (1999) theory on 'internet-mediation'. The authors conduct a theoretical discourse of the literature to
\end{abstract}


develop a framework consistent upon the VLC model proposed by Schwier (2007) and the three-phased integrative model of virtual communities as societies developed by Romm et al. (1997). The authors use an integrative 'quanto-phenomenographic' approach by employing a mix of descriptive and phenomenographic research. The analysis revealed that the socio-cultural values influenced the knowledge sharing process at two-levels i.e. the user level and the environment level yielding altogether 12 socio-cultural values which including nationality, integrity, trust, gender etc. which might inhibit the utility of a virtual learning environment.

Keywords: knowledge sharing, virtual learning community, socio-culturalism, culture, multiculturalism, virtual learning environment, phenomenography

\section{Introduction}

In today's globalized economy, 'knowledge' has emerged as a significant resource and an intangible asset critical to fostering innovation and creativity (Nonaka \& Takeuchi, 1995; Davenport \& Prusak, 1998). In the wake of an economic shift from industrial to information-based economy, knowledge constitutes a significant portion of the economy. These drastic changes have inspired researchers to investigate the ontological and epistemological perspective of 'knowledge' and the practices to which lead to managing 'knowledge' (Davenport et al. 1998). Ardichivli et al. (2008) argue that research on knowledge management has established a view of managing knowledge as a 'socio-technical system' concentrating on issues like creating, storing, disseminating and exploiting knowledge in the social context. However, emerging focus on knowledge sharing within communities of practice, communities of interests and communities of learning have been successful in addressing issues of managing 'human' and 'social facets' of knowledge creation and sharing (Wenger et al. 2002). Increasing research on knowledge management further indicates that processes like: 'communication', 'learning' and 'knowledge-sharing' are tremendously influenced by societal and cultural values (Ardichvili et al. 2008).

During the past decade, socio-cultural and economic factors of the globalized world have instigated a new blend of cultural mix where individuals are required to continuously communicate and network with colleagues originating from different cultures (Heizmann, 2009). In such a world where knowledge is at the core of every organization, the researchers were able to find very little research done on knowledge sharing in multicultural learning communities at the higher education level (Leary \& Fontainha, 2007). Certainly there has been research conducted on the intersection of culture in the field of knowledge management, but most of it focuses at the 'outset of national culture' (Heizmann, 2009). However, the researchers have employed an integrative approach using a unique quanto-phenomenographic approach to interpret a case-study of a group of students in a higher educational institute. The authors intend to capture a more holistic picture of the socio-cultural values in a multicultural student group involved in e-learning. 
The basic premise of this case study revolves around the concept of two theoretical views of internet-mediation and mind-mediation linked with the concept of virtual learning communities (Vygotsky, 1978; Thorne, 1999; Wegner et al. 2002; Romm et al. 1997; Schwier 2007). The researchers intend to investigate using the aforementioned two theories and assess the impact of societal and cultural values inherited by individuals that might inhibit the exchange knowledge through an online learning community. In order to pursue this research, a group of culturally diverse students from an MA cohort were selected from a higher educational institution situated in the north-western region of the United Kingdom (UK). The MA community is a tangible learning community (community of place and learning) which learns not only inside the classroom (in close proximity of their peers and tutors) but it is also designed to facilitate learning over the internet. This community is formulated on the basis of certain criteria set forward by the higher educational institution in its admission policy. The MA community is an agglomeration of individuals representing a wide-range of cultures from Asia, Europe, Middle-East and Africa having similar interests (course-related) inclined to achieving a common goal (award of an MA degree). The MA community as a part of its course structure is virtually linked through an online platform while the students are its users (members), who use this system to generate, store, share and utilize the course-related information with their peers and teachers.

\subsection{Mind Mediation vs. Internet Mediation}

Barachini (2009) has indicated that the research on the socio-cultural perspective of knowledge management has acknowledged the influence of social and cultural values on the process of knowledge sharing based on human thoughts \& expectations, biosocial and cognitive needs. Despite the increasing literature on knowledge management, this dimension requires further research especially from the learning communities' perspective. The concept of socio-culturalism can be traced back to the mid 1980's, when Vygotsky presented his research on child development. In an attempt to understand the socio-culturalism theory, Lantolf (2002) quotes Vygotsky's (1978) research on 'mediated mind' that:

"humans do not directly act on the physical world but rely, instead on, tools and labor activity, which allows us to change the world ........ We also use symbolic tools, or signs, to mediate and regulate our relationships with others and with ourselves and thus change the nature of these relationships"

In this statement Vygotsky indicates physical and symbolic tools as objects of human culture inherited by individuals which are established over a period of time. These symbols may formulate a society's way of thinking, art, lifestyle, or language with which they communicate with others and the world (Lantolf, 2002).

Thorne (1999) argues that 'internet mediation' has an impact on people from different countries who have a different first language (other than English). Furthermore, his theory indicates that the 'learners' communicative interaction' to a foreign language speaker changes when it is used through internet as a medium of communication. In a study he reports that 
foreign students did not feel any pressure while communicating on the internet as they were hiding behind their computers and interacting with others. Thus internet technology creates an environment where students felt free to discuss issues which they wouldn't have discussed face to face (Lantolf, 2002).

\subsection{Knowledge Sharing and Socio-Cultural Issues}

Bonifacio et al. (2002) suggests that knowledge sharing process comprises of sequential steps where knowledge is 'created', 'codified' and 'disseminated'. Once knowledge is codified it is ready to be disseminated or shared, but what happens when it reaches the human mind? Barachini (2009) attempts to answer this question by stating that different human brains codify or interpret knowledge according to their perception, context, experiences etc. In his research, Barachini (2009) has also referred to an 'autopoietic epistemology school', which relates knowledge as an individual's personalized intuition and links it to his/her values and beliefs. Hence it can be deduced that knowledge shared through techniques like storytelling, experiential learning, or discussions will be interpreted by an individual according to values and beliefs developed over a period of time (which may be influenced by society, national culture, organizational culture or personalized development etc.).

In a study, Husted et al. (2002) have studied the behavior of individuals and problems during the knowledge sharing process. They divide the knowledge sharing dilemmas into three distinct types. The first is the 'hoarding behavior' of the knowledge sender where the sender hesitates to share knowledge due to reluctant behavior in terms of insufficient time, loss of personal value, economic value, high exposure, power etc. The second type of dilemma is the receiver's 'rejecting behavior' which is triggered due to issues of validity and reliability of the sender's content or in light of one's own ideas or knowledge. The third dilemma is 'knowledge and environment', which includes uncertainty, attitudes, organizational culture that influences the sharing of knowledge. Moreover an important addition to the socio-cultural debate was added by Chow et al. (2000), who investigated the impact of national culture on knowledge sharing between US \& Chinese nationals on Hofsteadian constructs like 'individualism - collectivism' and 'dynamism'. However, this research was limited in its perspective to answer the impact of socio-cultural values on knowledge sharing within student cohorts.

\subsection{Role of CoPs and VCoPs in Knowledge Sharing}

The term 'community' was first used by Lave \& Wenger (1991) as 'communities of practice' (CoPs) during their research on situated learning (Hilderth \& Kimble, 2004). Lave \& Wenger (1991) as cited by Ardichivli (2008) define communities of practice as, "an activity system about which participants share understandings concerning what they are doing and what that means in their lives and for their community". Arguably, the most significant advantage of CoPs is its ability to facilitate the generation and exchange (sharing) of tacit knowledge with members of a particular community in context-specific environment (Nonaka, 1994). However, earlier research on communities of practice (CoPs) focused more on face-to-face and closely located communities before the introduction of virtual communities of practices 
(Wenger, 1998). Virtual communities of practice (VCoPs) are also, "a network of individuals who share a domain of interest about which they communicate online" (Leary \& Fontainha, 2007). It is an online social network where people can interact to share knowledge and engage in social interactions for example experiences, problems and solutions, tools, methodologies etc. (Chiu et al. 2006). Virtual communities of practice as online learning communities have gained widespread recognition among universities and educational institutes, fairly complemented by technological advancements, have increased communication and learning (Leary \& Fontainha, 2007).

Daniel et al. (2002) suggests that a virtual learning community is formed due to social interaction of community members on the internet. Researchers and theorists suggest that a virtual learning community may comprise of communities formed on the basis of similar interests (Croon et al., 2000), goals, ideas, places, reflection i.e. (Schwier, 2007) and corporate practices i.e. communities of practice (Wenger, 1998). McCalla (2000) indicates that virtual communities have two most common elements which are language and culture. These elements act as a bond which promotes participation by members (Daniel et al., 2002). Social interaction among these communities is encouraged by commitment of members to participate and share knowledge and experience. This does not refer that it creates trust but a possibility to connect with people and broaden one's knowledge acumen (Daniel et al. 2002).

Virtual communities have been discussed with great importance with reference to their knowledge sharing capacity (Wenger et al., 2002). These communities are continuously engaged in enhancing the learning of individuals by information exchange amongst the community members (Fontaniha \& Leary, 2007). Johnson (2001) has supported the concept of knowledge sharing in virtual communities by stating that, "the learning that evolved from these communities is collaborative, in which the collaborative knowledge of the community is greater than any individual knowledge". This also compliments Vygotsky's (1978) concept of learning that individual learning can be enhanced by engaging with other people, and developing one's own capabilities by the exchange of ideas and knowledge. Wenger et al. (2002) supports this concept by indicating that networked learning can improve the quality of learning where knowledge sharing is through social interactions.

\section{Theoretical Framework}

The theoretical framework is based on an in-depth discourse of the literature on virtual learning communities and its relationship with socio-cultural values. The theoretical framework draws its foundation from an interface framework developed to identify the placement of the virtual learning community (group of students) studied in this research. The interface framework has been designed and developed by using two comprehensive models on virtual communities proposed by Schwier (2007) and Romm et al. (1997). The theoretical framework is a bi-product of the interface framework which maps two models into one creating a blue-print of the research. The two models are explained briefly below: 
2.1 The Virtual Learning Community Model - as proposed by Schwier (2007)

In a series of grounded theory studies on virtual learning communities of graduate students, Schwier (2007) developed a comprehensive model which describes the formulation and design of a virtual learning community (VLC). The model divides a VLC in three parts: a). elements essential to a VLC; b). types of VLCs; and c). catalysts of VLCs. The three components combine to formulate a virtual learning community and determine its nature, intent and goals.

\subsubsection{Elements of a Virtual Learning Community}

Schwier (2007) proposed that there are thirteen essential elements which combine to formulate a virtual learning community. Originally identified by Selznick (1996) in a study of terrestrial CoPs six elements were identified while seven more were added by Schwier (2007). These elements are a part of a typological formation of virtual learning communities. Each element corresponds to a certain meaning associated with the learning community. The elements along with their corresponding meanings are tabulated in appendix - A1.

\subsubsection{Type of a Virtual Learning Community}

Schwier (2007) argues that, "virtual learning communities are based on a shared purpose rather than geography". Extending the research work of Kowch \& Schwier (1997), if provided with technology, learners can utilize it to formulate an online community. Furthermore, they have described as many as five classifications of VLC's which are: communities of relationship, communities of place, communities of intent, communities of reflection and communities of ceremony. Each type of virtual community is described in a tabulated form at appendix - A2.

\subsubsection{Catalysts of a Virtual Learning Community}

Schwier (2007) describes 'communication' as a core factor which acts as a catalyst in a virtual learning community. It generates awareness, interaction, engagement and alignment and in online learning communities by providing the life-blood, "the communication". Each stream of communication is described in a tabulated form at appendix - A3.

\subsection{Virtual Communities and Society - as proposed by Romm et al. (1997)}

In a research on the societal and cultural aspects of virtual communities, Romm, Pliskin \& Clark (1997) proposed a three-phased integrative model that focuses on 'three building blocks' as termed by Romm et al., (1997). These building blocks include: a). variables that affect individuals' perception; b). variables that affect the immediate environment of a virtual community; and c). variables which explain virtual communities as 'transforming societies'. Each variable enlisted by Romm et al., (1997) includes sub-variables which play a significant role in accumulating the impact of each variable onto the virtual community.

\subsubsection{Variables Affecting Individuals' Perception}

During the mid-80's studies generally focused on individuals' perception and willingness to 
be a part of a virtual community. In this regard Romm at el. (1997) has identified four variables from previous literature: technological, motivational, task and system-level issues to affect an individual's orientation, perception and attitude towards a community. Description of the variables is tabulated at Appendix - B1.

\subsubsection{Variables Affecting the Environment}

In recent studies it has been observed that virtual learning environment is affected by the membership profile of the community and acts as a dominant variable in assessing the exchange of knowledge in such environment. Romm et al. (1997) has identified four variables of community members that affect the immediate environment of the virtual community, these are linguistics, politics, social and performance. These variables are visited briefly to clarify their impact on knowledge sharing in virtual communities at appendix $-\mathrm{B} 2$.

\subsubsection{Variables Transforming the Community}

These variables identified by Romm et al. (1997) are based on the research conducted by Falk (1995). The variables here include: integration of national identity, community integration / fragmentation, redefining personal relationships and integrating production systems. These variables are explained briefly in tabulated form at appendix $-\mathrm{B} 3$.

In order to develop a logical framework to pursue the research, the two models were compared for similarities and differences. The interface framework integrates the models through a mapping technique which identifies the road map for this case study. For the convenience of the readers we shall indicate Schwier (2007) model as 'A' and Romm et al. (1997) model as 'B'.

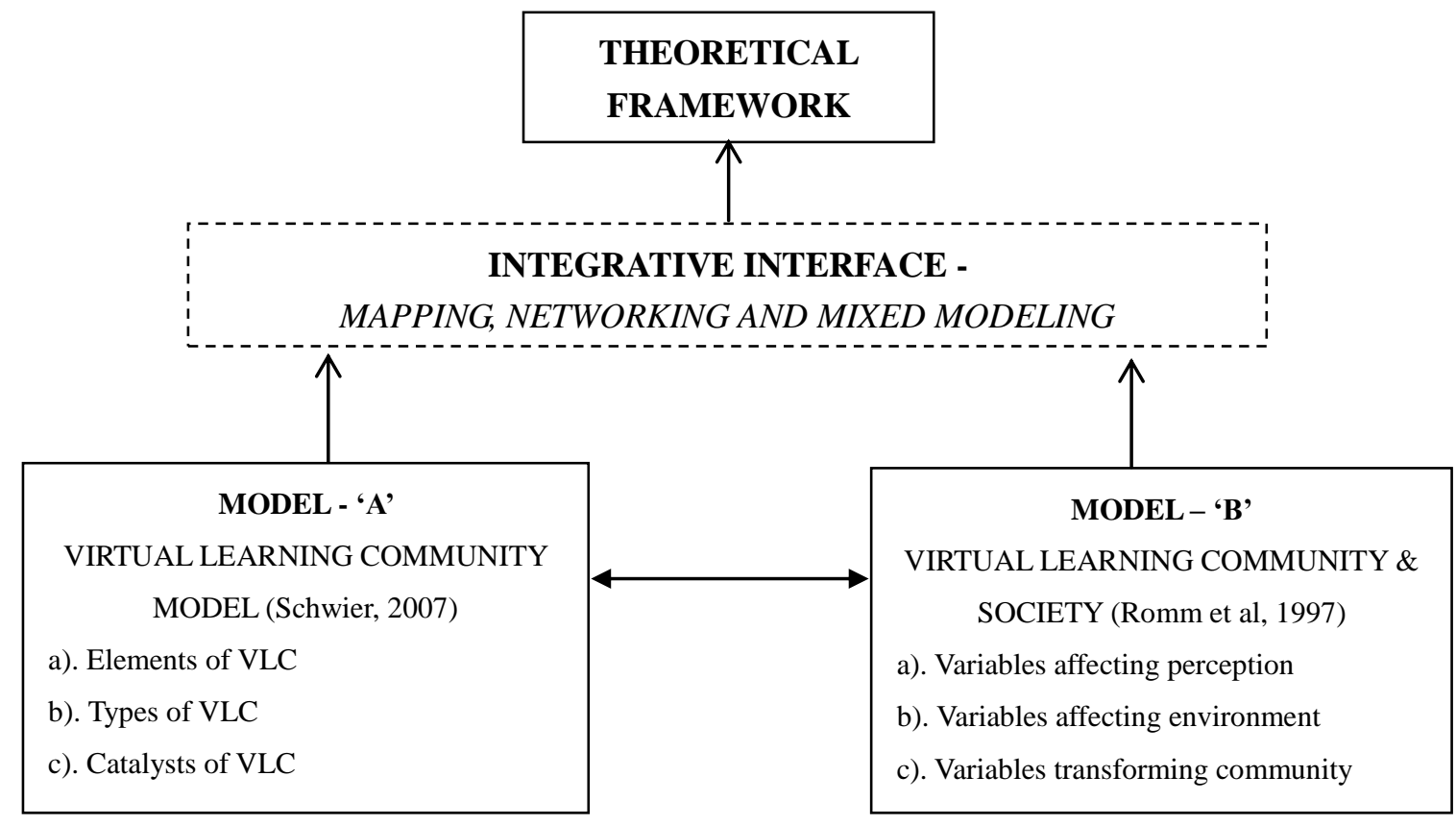

Figure 1. Integrative Interface 1.0 
The integrative-interface processes the models using the mapping technique as follows:

- The mapping process shall begin from model - 'A' and use a backward integrative approach which starts from the macro and proceeds towards the micro environment of the virtual learning community.

- Each component of the model shall be interconnected with its corresponding component with a unique color highlighting its association.

- The model ' $A$ ' and ' $B$ ' shall be integrated using the core values which are mutually exclusive to the 'community' and community as a 'society'.

- The components from model - ' $\mathrm{B}$ ' shall depict the layers at which this research is conducted. Integrative interface provided the means to identify the target areas of this research prior to commencement.

Illustration of the Integrative Interface: The group of students selected for this research study are located in close vicinity where they are able to interact within and outside the classroom using the virtual learning community. The model - ' $A$ ' is used initially using the backward integrative technique. The community selected for this study by description of its characteristics is known as a 'community of place'. Each community utilizes the catalysts which facilitate communication amongst community members. The catalysts (with their sub-catalysts) correspond to some elements (values) which develop a community or at the core of the community. These elements are associated with the societal view of the virtual communities using Model - 'B'. Further the model is then divided into layers used for this research. The integrative interface during the mapping process can be seen at Figure - 2.

The integrative interface is now interpreted into a theoretical framework by the process of layering and de-layering to identify categories or target areas of socio-cultural interventions. In order to conduct the process the researchers base their extractions on the socio-cultural design principles proposed by Hall (2007). These principles revolve around six factors which are affected by socio-cultural values, especially in a culturally diverse student cohort. These principles constitute of: a). aim of the course; b). learning context; c). instructor's role; d). role of peers; e). activity in the course; and f). initial context (Hall, 2007: p.9). In light of the above, socio-cultural interventions impact the sharing of knowledge and learning outcome, as indicated in the integrative interface yielded the following propositions:

P1. Individual perception of the member may impact the quality of knowledge sharing.

P2. Individual perception of the member may impact the learning environment - the learning environment in this case shall be called the virtual learning environment (VLE).

P3. The perceived learning environment of community members impacts the actual learning environment.

P4. The community membership impacts the learning outcomes and knowledge sharing. 


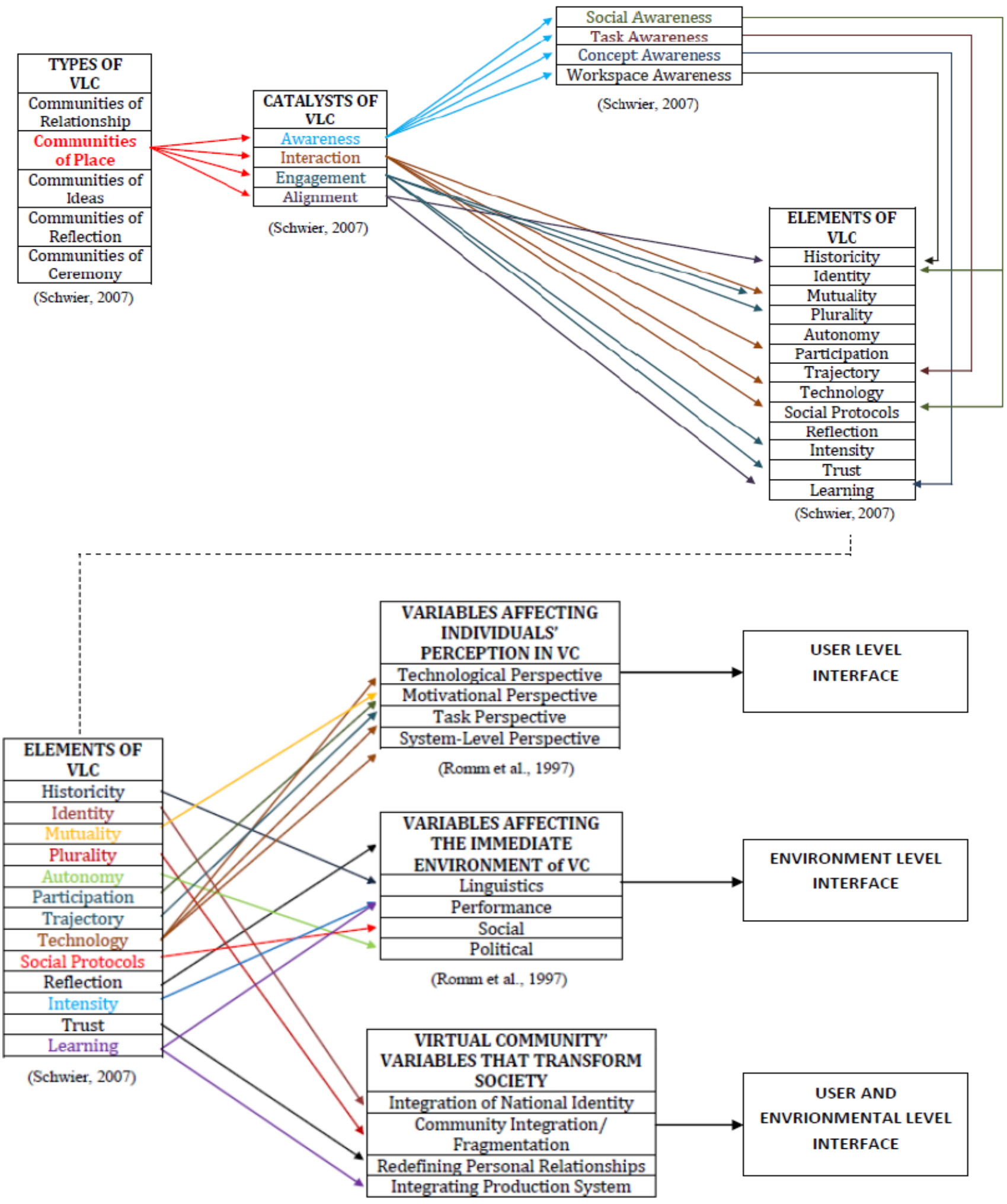

Figure 2. Integrative Interface - Level 2.0 (Adapted Model) 
The aforementioned propositions can be divided at two levels i.e. the user level (member level) and the environment level (community level). Based upon the discussion in the literature and theoretical and integrative interface the transfer of knowledge from the sender to the receiver may be subject to socio-cultural values at the user and environment level. Therefore, the variables which impact the knowledge sharing at both the levels are of great significance to our case study.

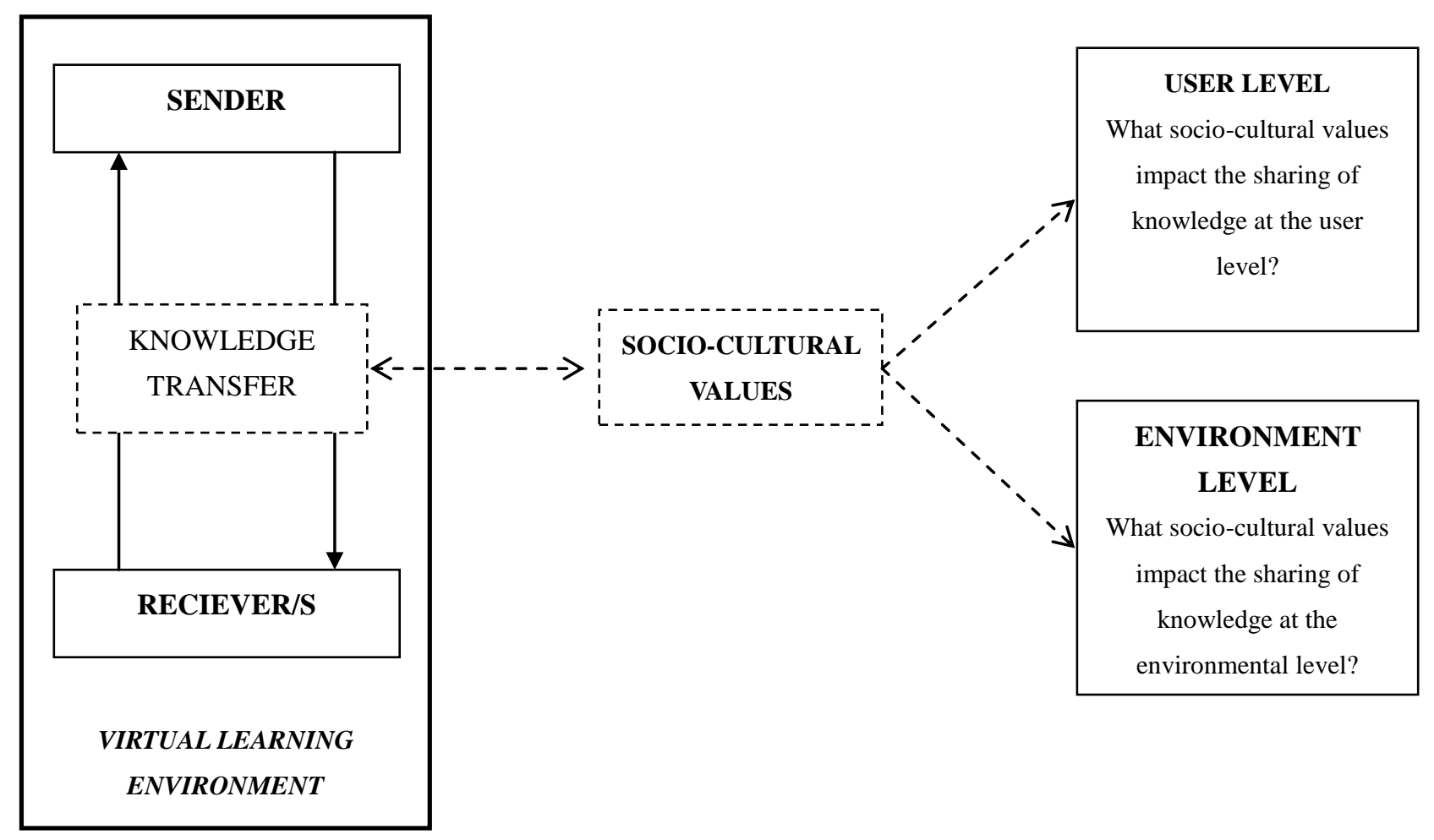

Figure 3. Theoretical Framework

\section{Research Strategy and Analysis}

Bryman (2006) argues that employing a specific research methodology is driven by a commitment to uncovering data of a particular type which matches the needs of the research. In order to choose the right methodology, researchers suggest that the purpose of the research should always be kept in mind as a guideline (Cohen et al., 2007). The researchers in this piece of study try to uncover the impact of socio-cultural values on knowledge sharing which are at the core of every society. Furthermore, the research has been broken down into three research areas: a). identification of the socio-cultural values at the user and environment level; b). knowledge sharing behavior of community members; and c). the utility of a learning environment. The areas of research have been extracted from the theoretical framework through a detailed process of integration and discursive analysis.

Easterby-Smith et al. (2003) suggests that if a research involves probing into existing practices, models or techniques implemented in different setups, environments or contexts, 
then 'evaluation research' is a possible option. In alignment with the purpose of this study, the researchers focus on using evaluation research approach. The field of evaluation research and others alike have established a strong support for using a multi-strategy case or mixed methodology (Tashakkori \& Teddlie, 2003). The researcher believes that using such a distinctive research methodology has its own right that warrants its inclusion as compared to the traditional approaches (Brannen, 1992). The methodology used in this case study is unique in its sense to identify research findings in an orderly fashion presenting facts with more sense of rigor by attributing itself to the strengths of two distinct approaches (Creswell, 2003). The research strategy is a combination of quantitative - descriptive statistics and phenomenography - which shall be known as 'quanto-phenomenography' for the ease of readers.

The reason behind using a quantitative approach with a qualitative approach is to provide more clarity in the data set and results. The descriptive statistical approach is not entirely a quantitative approach or a qualitative approach. But it is an efficient way to cross-sectionally study the research participants. The descriptive statistics is easily used in any form of quantitative and qualitative research despite its critics. The procedure to apply 'quanto-phenomenography' in this case-based approach is described below:

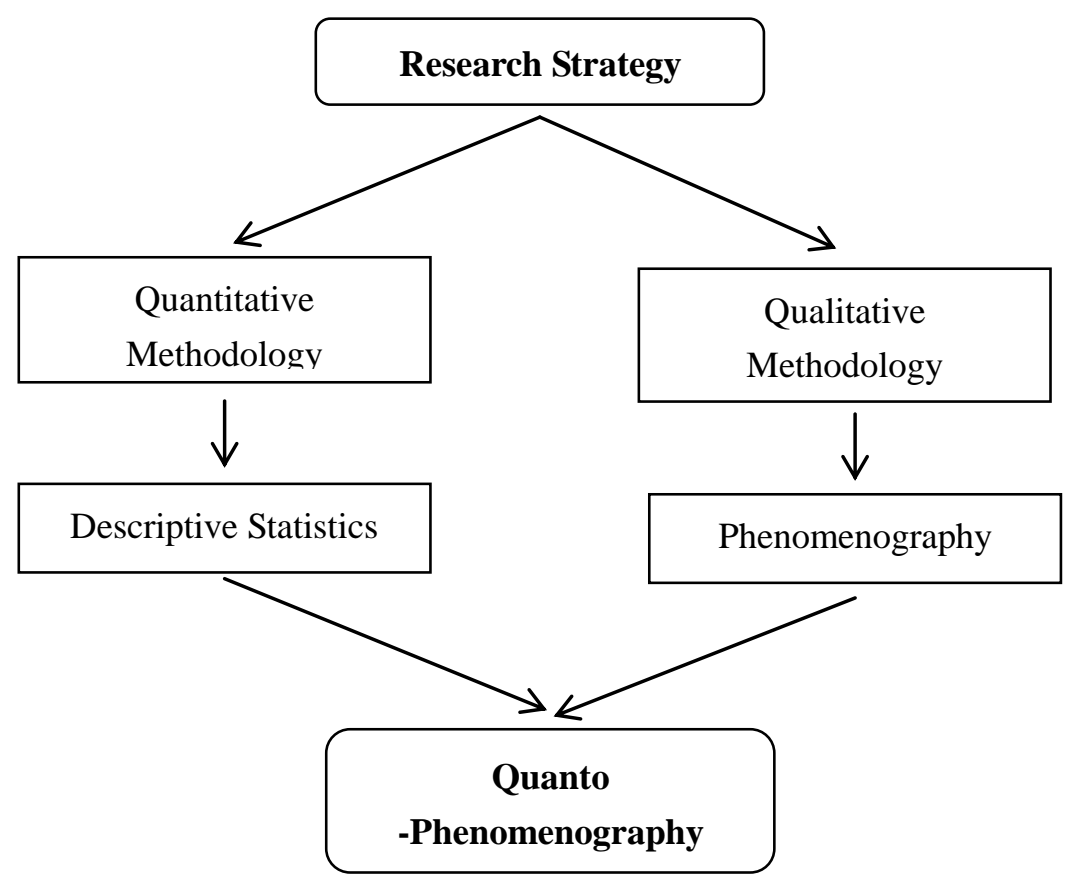

Figure 4. Research Strategy Formulation - Quanto Phenomenography Approach

\subsection{Descriptive Statistical Approach to Quanto-Phenomenography (Part - I)}

Glass \& Hopkins (1984) suggest that descriptive statistical approach involves gathering of data pertaining to attributes, events and variables which are then organized for analysis in tabulated or graphical form. Data gathering pertaining to statistical description of data sets 
has been used quite often by researchers in the field of education, communications and technology to identify open and closed patterns of study (Gunawerdena et. al, 1994). The researchers believe that due to its nature of simplicity and ability of providing a cross-section of the data, descriptive statistics will be an effective approach to be integrated with qualitative - phenomenographic mode of research. The descriptive research conducted in this case is described as follows:

- The quantitative approach employing descriptive statistics was used initially to create a participant profile (profile of the community members) for detailed study.

- To create a participant profile data pertaining to their demography, ethnicity, nationality, work-life and course-related information was gathered through an online questionnaire survey.

- The data-set collected was analyzed for similar connotations and grouped according to categories such as gender, language, nationality, background and course profile etc.

- In the latter half of the survey participants were inquired about various components of their virtual learning environment (the online system) on a 5.0 likert scale for the most common socio-cultural values. The data pertaining to this was compiled, analyzed and compared to the participant profile for detailed discussion for in-depth interviews.

- The data pertaining to the latter half of the survey was tested for reliability and validity while the most significant socio-cultural attributes were tested for deviation statistics for creating a deep-understanding of issues in interview sessions.

\subsection{Phenomenographic Approach to Quanto-Phenomenography (Part - II)}

Phenomenographic research has been termed under the qualitative paradigm of research, which according to Entwistle (1984) is distinctive from due to its ability to describe variations in human meanings, conceptions and experiences. Webb (1997) has termed phenomenographic research to be 'emphatic' and 'exceptionally rigorous' in its ability to identify 'sociological variants'. This portrays the core idea of phenomenographic research that there is a logical relationship among the ways of experiencing and a particular phenomenon, it may be through a 'hierarchical' set of relationships (Morton \& Booth, 1997). The research in phenomenographic research does not only gathers the different meanings associated but also the 'relating structure' which relates the individual ('experiencer') and the 'phenomenon' (Morton \& Booth, 1997). Akerlind (2005: p.323) suggests that this relationship provides an opportunity for "looking at the collective human experience of phenomena holistically, despite the fact that the same phenomena may be perceived differently by different people under different circumstances". In our case the members are experiencers while the virtual learning environment is the phenomena about which they have established values which may inhibit the sharing of knowledge. The phenomenographic approach is used in the following way:

- The researchers after having collected and studied the descriptive research data now selected participants from each category which they created. The participants selected for the interviews were known as 'group representatives'. 
- Instead of interviewing the whole group of students, the researchers already collected data pertaining to their values through the questionnaire technique while group-reps were questioned and cross-questioned in the interview sessions for their experience of having communicating and educating on the virtual learning environment.

- The interview questions were based on a general picture of their group, therefore, no specific questions were asked of group-reps which they wouldn't have managed to answer.

\subsection{Data Collection Methods}

The data collection was conducted in two stages. The first stage involved gathering of descriptive data from the group of participants while the second stage involved gathering of experiential data from the members to evaluate their experience of sharing knowledge over the virtual learning environment.

\subsubsection{Questionnaire Survey}

The questionnaire was divided into two parts. The first part was directed at gathering data pertaining to the student groups' background, nationality, demography, ethnicity etc was collected. The second part of the questionnaire was aimed at collecting data pertaining to virtual learning environment, community and the most significant values perceived by the members. This survey was conducted to collect the data from all the 50 students in the MA group.

\subsubsection{Interview Sessions}

The interview sessions were aimed at the data collected earlier in the questionnaire phase. The questionnaire data was cross-referenced based on the experiences of student group representatives. A total of 12 representatives were selected based on their ability to represent a group based on certain indicators such as gender, nationality, age and ethnicity. Each interviewee was given a pseudonym keeping in view the ethical issues of confidentiality. The experiences of group-reps were used to identify what socio-cultural values were perceived to be more significant at either the user or environment level. The participants were assigned pseudonyms (with alphabet letters).

\subsection{Participant Profile through Descriptive Statistics}

The participant profile was created using the descriptive statistical data collected through the questionnaire survey. The study sample for the questionnaire survey consisted of Indian 26.4\%, Chinese 21.5\%, Pakistani 10.5\%, while Egyptian, Cyprian, Kazakh, Japanese, Taiwanese, Korean, Saudi Arabian and Indonesia each contributed at 5.2\% (See Figure - 4). The gender ratio in the study was $76 \%$ females and $24 \%$ male students (See Figure - 4), while the average age of the study sample was in between 21-25 years. The frequency of computer and internet usage varied between daily to weekly while frequency for using the virtual learning environment varied between weekly to monthly. 

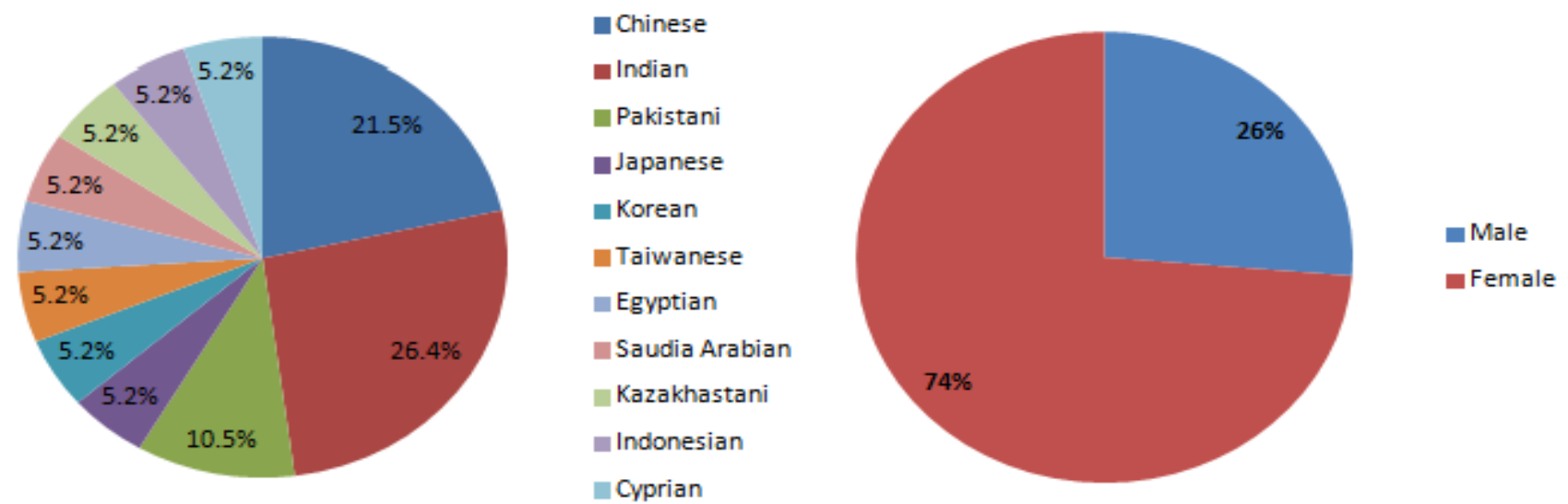

Figure 5. Distribution of the Study Sample

\subsection{Analysis of the Descriptive Data}

The quantitative part of the research pertaining to the questionnaire survey was meant to test the model for validity and reliability so that the model could be used for implementation in a qualitative interview study of the participants. The 10 items on the questionnaire regarding gender, politics, individualism, national culture, language, loosing face, contextual similarity, social networking, multicultural society, learning, and knowledge sharing were measured on a psychometric likert scale. Firstly, the items on the questionnaire were checked for internal consistency using the Cronbach's alpha test, which yielded a result of $\alpha=0.8322$. The questionnaire was then administered to the respondents. Secondly the analysis of questionnaire responses indicated an average response mean value at $u=2.7$ (central) (See Figure -4$)$, while the standard deviation resulted at $\sigma=0.8$.

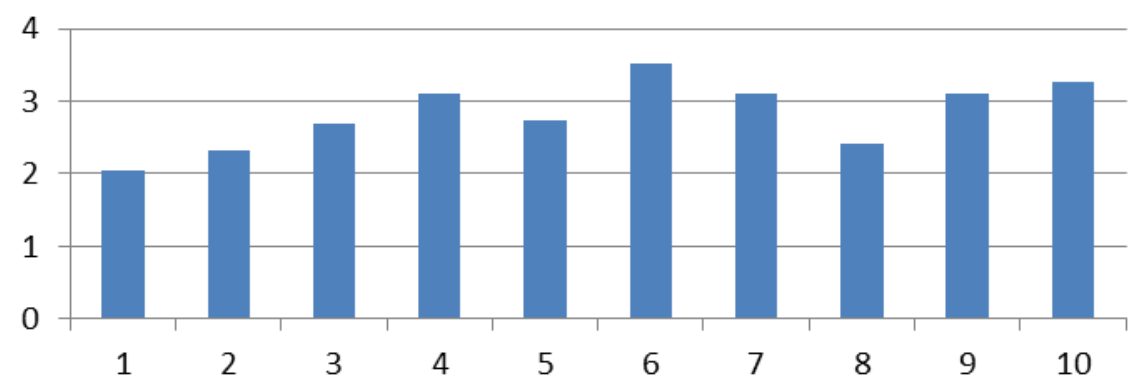

Figure 6. The Mean Values of the Answers - (u)

The analysis also highlighted that there were potential traces of socio-cultural values (SCV) which must be investigated through a qualitative research to get a more holistic picture of the influences and impact which the respondents thought to either facilitate or hinder the process of information exchange. Therefore, the author then conducted a series of semi-structured interviews to ascertain the impact of SCV in qualitative terms. 


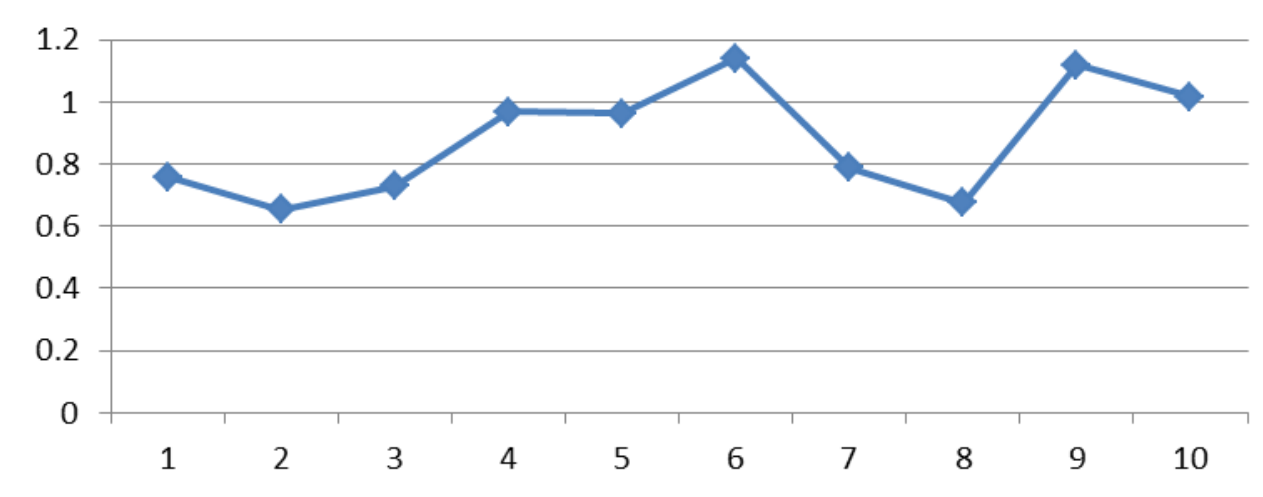

Figure 7. The Standard Deviation of Answers - ( $\sigma)$

\subsection{Analysis of the Phenomenographic Data}

Phenomenographic analysis seeks to describes, analyze, develop shared understandings and indicates variations in the data schemes (Marton, 1981). The emphasis is more on description socio-cultural values by highlighting any similarities and differences in the meanings articulated by individuals (Svensson, 1997). Pang (1999) indicates that the focus of phenomenographic analysis is on variation (both in the 'way of perceiving' and 'way of experiencing' of phenomena). It is important to reiterate the fact that a phenomenographic data is used for 'collective analysis of individual experiences' (Akerlind, 2005). Therefore, researchers must aim to draw a conclusive picture of an individual's perception and experience as complete as possible for contributing to the greater image (Marton \& Booth, 1997).

Akerlind (2005) suggests that interviews are the most important source of data for a phenomenographic research, while, interviews are transcribed to gain a deeper insight to the range of meanings individuals associate towards a particular phenomenon in this case the emphasis was on socio-cultural values. Phenomenographic interviews are usually audio-taped and then transcribed verbatim, hence making the transcripts a vital component for analysis (Akerlind et al., 2005). In light of this, the researchers transcribed each of the 12 audio-taped interviews conducted with the group-reps. The analysis on the interview data was done in three steps:

- The data collected through interviews was coded by using qualitative or open coding scheme (Ryan \& Bernard, 2003). Each impression was identified from the transcript which was then given a suitable contextual meaning or multiple meanings.

- Once the coded schemes were developed, each impression was then put under a certain category of description (CoDs) (Cousin, 2009; Bowden \& Marton, 2004). Each category of description indicated a set of themes and sub-themes useful to the case. 
- Lastly, prioritizing and clustering of themes into main and sub categories were done (Ryan \& Bernard, 2003). These were divided keeping in view the most significant socio-cultural values perceived by the group-reps.

\section{Results and Discussion}

The data streams collected during the course of this research are in alignment with the theoretical framework and the research question. The thorough data analysis yielded various findings which have been documented under each socio-cultural value which have been perceived to be the most significant effecting the sharing of knowledge. Each socio-cultural value has been identified and discussed for its ability to impact the knowledge transfer process within the learning environment. Each Socio-Cultural Value (SCV) found in the data streams have been described briefly along with extracts from the interview sessions with group-reps (not specific to any culture in particular but general in nature).

\subsection{SCV-I: Socio-Technical Perspective}

Community members from the socio-technical perspective of the virtual learning community described the VLE (virtual learning environment) as too 'generic', 'open' 'feature-less', and a 'non-updated' system which requires thorough updation incorporated with learning enhancement features. Most of the participant expressed their feelings and experience of using the VLE in an identical manner which indicated of the wide-spread community view regarding the learning environment. In response to one of the questions regarding the purpose of the VLE, one of the MA students (community member) said:

"Yes for a common student it's a common system, but there are certain factors that apply over here. One of the most important factors is the worth or value of data / information being shared and then only it can be assessed that the VLE is serving its purpose and is a reliable system. However, the environment and community are responsible and the knowledge shared to me is not worth the value for the system [....]." (Student A).

\subsection{SCV-II: Emotions and Feelings - "Change"}

Pertinent to the feelings and emotions of the community members regarding the adoption of a new form of communication i.e. from face-face to technology based communication, most of them regarded the change as 'welcoming' and showed their desire to gear up for the modern day world. However, everyone had a different perspective on 'change', some termed it as, "Instability", "Inevitable", New Opportunity", "Constant" - this highlighted that some community members feared change and some thought of embracing change. The interviewer asked whether the transformation or change from old form of learning and communication to the newer form had an impact, one member pointed out that,

"This change came gradually. I did not feel any instability. My first formal interaction with an educational system came when I was a student to the undergraduate program. I tried assessing the situation and made the change, although I had to experiment a 
lot to gain knowledge about the new form of communication i.e. online, but the desire for experimentation in VLE has been limited" (Student C).

\subsection{SCV-III: Motivation and Task-Level}

On the construct of motivation and task level regarding the community members towards VLE, the author got similar perspectives from all of the students in the community. Everyone seemed to have noticed the there is little motivation to work on VLE and use other forms such as emails, phone, personal meetings etc. which decreases the utilization of the system. The author inquired from the members whether there is a lack of participation on VLE from the community members, most of the responded as:

"Yes, I do. If you look at the number of profiles of users and the level of their usage and postage on VLE it is quite evident that they are either passive users or are not interested in using the system. I know one can survive without it as there is no compulsion towards its usage unlike other learning environments in the University" (Student H).

\subsection{SCV-IV: Language (Linguistics)}

The community members thought of language as a basic necessity to communicate with others, but in a multicultural society like the MA HRD \& Consulting Community have a common language was considered important. However, some thought of language presumably 'English' (not their first language) to cause barriers to communication. One of the students added to the discussion that systems around the world are mostly employing nation-based languages, as:

"For me a common language i.e. an international language like English at times causes. Before posting threads or discussions I have to think about the right sentences conveying the exact meaning, grammatical errors and errors of communication before proceeding. [...] that is why I prefer facebook in my own language even some email servers too". (Student $G$ )

\subsection{SCV-V: The Societal View of VLE}

The societal view of VLE has set the social values for the community members. The social views of the members have developed pre-conceived notions of their community which has led to the decrease in sharing of knowledge and utilization of the VLE (virtual learning community). Students' term their VLE community as:

"I think inside the classroom we are an active unit, but outside and online we only limit ourselves to emails. We don't use VLE that much because emails are more focused dependent and there are fewer interruptions, but the level of learning and knowledge sharing is low using emails than it would be using an educational system like VLE.” (Student ,„J") 


\subsection{SCV-VI: Politics and Power Relations}

There was no evidence collected on this construct, however some of them posed their concern whether VLE being open to tutors may at some point of time cause power - relations to intervene.

\subsection{SCV - V: National Culture / Identity}

It was very difficult to measure this construct because there were various aspects associated with national culture, so the author had to indirectly inquire about the effect of national culture on the virtual learning community. The members indicated various factors like, language, culture ethics of being straight forward or not being straight forward, being too open or reserved meant different things in different cultures. However, the members indicated that in order to communicate with others one must take time to understand their culture.

"Certainly, it is not easy to communicate to people from other countries instantaneously. One must first try understanding that in other person's culture what certain words mean so that he/she doesn't feel's offended." (Student K)

\subsection{SCV - VIII: Community Fragmentation / Integration}

This value indicated that tacit knowledge remains with the individuals and is not shared frequently. The members have noticed small communities of practice within the learning community which might act as a barrier to social interactions and limit an individual's interaction with others. One student quoted:

"Certainly there are, especially based cultures, friendship, or may be gender. It is human nature and everyone looks for his/her maximum interest. So being or mingling among people from one's own interest is natural. Communities of interest you can call them, especially in group work or discussions you can find alliances not only based on culture but also on persuasive or friendship grounds". (Student D)

\subsection{SCV-IX: Personality}

This was an additional construct which came into notice during the questionnaire phase. Most of the community members reckoned personality to be an intrusive value which may be an important factor influencing the sharing of knowledge (positive or negatively). The characteristics attributed with personality were mostly the „degree of socialness ${ }^{\text {ee }}$ of members, the flexibility, openness, participative nature etc.

"Well, it is a good question. I have noticed that personality plays a key role because when you an inquisitive nature you also try exploring and in it you communicate with others frequently to answer your curiosity [................] for me, I believe that characteristics like: Shyness, timidity, degree of socialness, leadership skills do matter while communicating (Student A) 


\subsection{SCV-X: Gender}

The comments received by the author under this value were mixed. However, males responded with more emotions and feelings as compared to the feelings. The questionnaire survey conducted earlier showed a gender imbalance in the community. One of the community member responded to as question under this value, as:

"If there were more males as compared to females, then the scenario would have been a bit different, because I believe that males are more into sci-fi technology stuff. The interaction online would have been prompt, however, if there were to be a debate regarding a gender issue, the males would be outnumbered". (Student I)

\subsection{SCV-XI: Trust}

The community members perceived trust as the basis of any social interaction especially in an online community. High levels of trust are required in online communities where you don't know the other person, but in tangible yet online communities one feels more confident in contributing to people where mutuality is considered to be the core idea of the community.

"Yes, because when you know that community members are trusted to be dedicated towards the goal and are trustworthy to be discussed like ideas, issues and matter then one communicates on frequent basis otherwise the usage falls down". (Student E)

The socio-cultural values influencing the knowledge sharing process are at two distinct levels are (i) the user level values and (ii) the environment level values. The values have been clustered into user and environment level due to their association with each level. These values differ from each other, as the first level is associated with the individual values (self-values) while the second is related to the system (learning environment). During the process of knowledge sharing from user - A to user - B (sender to receiver) in an online learning community, the knowledge is subject to influence by what does the user - ' $A$ ' think, the background knowledge, experience, education, culture, values associated about the community, goals, desire, self-interest etc. However, the knowledge will also be influenced by the environment in which the knowledge has been shared (whether it will be distorted or not), does the system has adequate information carrying capacity, is the system rich (with feature) to ensure frequent interaction, is there a culture which enforces online learning along with off-line classroom based learning.

The first level is the 'user level', where the user is in direct contact with the community members. The user has a certain level of artifacts which influence the knowledge sharing process. The values which affect the process of information exchange are:

SocioTechnical

Personality 
$\square$ Emotions, Feelings and Desire

Community Fragmentation

Language

National Identity / Culture

$\square$ Gender

The second level is the environment level. The environment here is referred to the virtual learning environment itself. The socio-cultural values that precede individualistic values and are directed towards the 'system' also impact the knowledge sharing process. The environment level values are:

\section{Applied Techno Perspective \\ Community-Oriented \\ StructureOriented \\ Environment-Oriented \\ CultureOriented}

Recalling the theoretical framework, we can place the aforementioned socio-cultural values in their respective dimensions or levels. Therefore, the modification in the theoretical framework and which shall be our conceptual model is placed at figure -8 for further review.

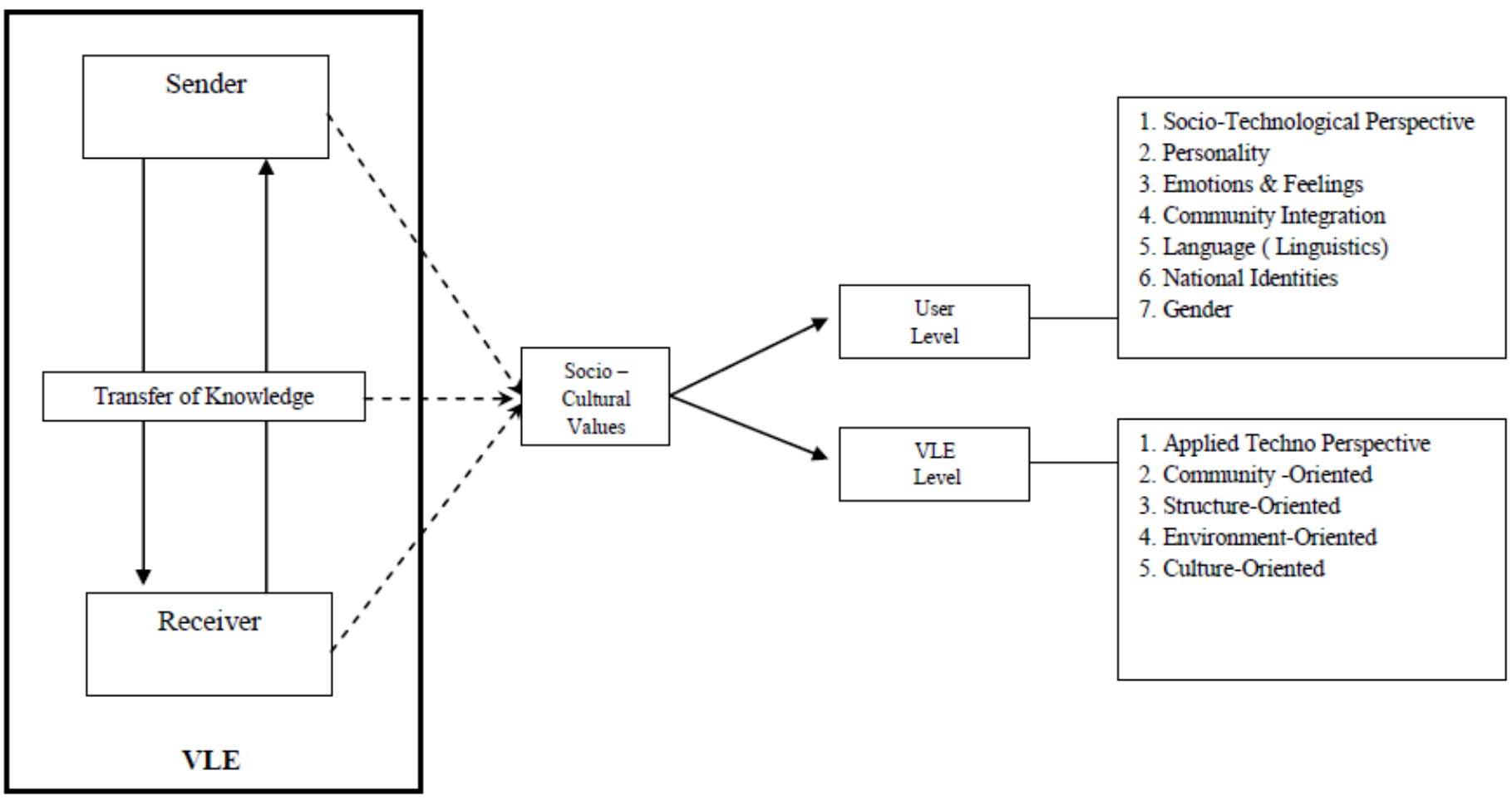

Figure 8.Conceptual Framework 


\section{Macrothink

\section{Implications}

This research is limited to the online learning communities within the higher education institutions (HEIs) therefore it cannot be generalized for virtual learning communities in organization on the national and multinational basis. Furthermore, individuals from different countries tend to perceive things differently, so the results may tend to vary considerably from one extreme to the other. The findings are mostly based on environment level values, whereas, user-level values must be investigated deeply.

\section{Conclusion}

The study highlighted a factual and a logical link between the socio-cultural values and their influence on the knowledge sharing process in networked learning communities. Furthermore, the study also showed that socio-cultural values may limit the utility of a virtual learning environment therefore it may reduce the learning capability of an individual. Hence, institutions must consider such social and cultural interventions before employing virtual learning environment for learning and knowledge sharing. The study acknowledges the models presented by Schwier (2007) and Romm et al. (1997) which acted as the foundation upon which a conceptual model was generated. The conceptual model will help academics and ICT experts to consider the socio-cultural values prior to designing and developing virtual learning environment for students belonging from different parts of the world. 


\section{References}

Åkerlind, G. S. (2005). 'Variation and Commonality in Phenomenographic Research Methods', Higher Education Research \& Development, 24 (4), 321-334

Ardichvili, A. (2008). 'Learning and Knowledge Sharing in Virtual Communities of Practice: Motivators, Barriers and Enablers', Advances in Developing Human Resource, (10).

Barachini, F. (2009). 'Cultural and Social Issues for Knowledge Sharing', Journal of Knowledge Management. Vol. 13 No. 1, pp. 98-110

Bonifacio, M., Bouquet, P. and Cuel, R. (2002). 'Knowledge Nodes: The Building Blocks of A Distributed Approach To Knowledge Management", In Proceedings of I-Know, Journal of Universal Computer Science.

Bowden, J., \& Marton, F. (2004). University of learning. London: Routledge.

Brannen, J. (1992) Combining qualitative and quantitative approaches: an overview. In Brannen, J. (ed) Mixing Methods: Qualitative and Quantitative Research. Aldershot: Avebury.

Bryman, A. (2006). 'Integrating Quantitative And Qualitative Research: How Is It Done? 'Qualitative Research, 6, 2006, pp. 97-113.

Chiu, C., Hsu, M., \& Wang, E. (2006). 'Understanding Knowledge Sharing In Virtual Communities: An Integration of Social Capital and Social Cognitive Theories', Decision Support Systems, 42(3), 1872-1888.

Chow, C.W., Deng, F.J., and Ho, J.L., (2000). 'The Openness Of Knowledge Sharing Within Organizations: A Comparative Study of the United States and the People's Republic of China', Journal of Management Accounting Research (12) 1, pp 65-95.

Cohen, L., Manion, L., \& Morrison, K. (2007). Research Methods in Education, (6 ${ }^{\text {th }}$ Edition), Routledge

Cousin, G. (2009) Strategies for Researching Learning in Higher Education: An Introduction to Contemporary Methods and Approaches. London: Routledge.

Creswell, J. W. (2003). Research Design: Quantitative, Qualitative, and Mixed Methods Approaches, SAGE Thousand Oaks

Croon, A., Erik, S. \& Agren, P. (2000). 'Virtual Communitiesó: Why and how they are studied'. Department of Informatics: Umea University, Sweden 
Daniel, B., McCalla, G. and Schwier, R. (2002), A process model for building social capital in virtual learning communities, In International Conference on Computers in Education, Vols I and II, Proceedings, pp. 574-575.

Daniel, B., \& Schwier, R.A. (2007). 'A Bayesian Belief Network Model Of A Virtual Learning Community', International Journal of Web Based Communities, 3(2), 151-169

Davenport, T. H. \& Prusak, 1., (1998). 'Working Knowledge: How Organizations Manage What They Know'. Harvard Business School Press, Boston.

Davenport, T. H., de Long, D. W. \& Beers, M. C., (1998). 'Building Successful Knowledge Management Projects', Sloan Management Review 39(2),p. 43-57.

Easterby-Smith, M., Thorpe, R. \& Lowe, A. (2003). Management Research (2 ${ }^{\text {nd }}$ Edition), London : Sage Publications

Entwistle, N. (1984). 'Contrasting Perspectives on Learning', In Marton,F. \& Hounsell, D. \& Entwistle, N. (Eds.), The Experience of Learning. Edinburgh, Scottish Academic Press

Falk, J. (1995). "The Meaning of the Web", [cited online]: URL: http://www.uow.edu.au/public/faculties/arts/sts/-ww/jfalk.htmI-Jim

Flyvbjerg, B. (2006). 'Five Misunderstandings About Case-Study Research', Qualitative Inquiry 12(2): 219-245.

Fox, S. (2005). 'An Actor-Network Critique Of Community In Higher Education: Implications For Networked Learning’, Studies in Higher Education, 30 (1) 95-110

Glass, G. V., \& Hopkins, K. D. (1984). Statistical Methods in Education and Psychology (2nd ed.). Englewood Cliffs, N. J.: Prentice-Hall.

Gunawardena, C. N., C. Campbell Gibson, J. J. Cochenour, T. Dean, C. L. Dillon, R. Hessmiller, K. Murphy, L. L. Rezabek, \& F. Saba. (1994). Multiple perspectives on implementing inter-university computer conferencing, In The proceedings of the distance learning research conference, 101-117. College Station, TX: Texas A\&M University, Dept. of Educational Human Resource Development.

Hall, A. (2007). 'Vygotsky Goes Online: Learning Design from a Socio-cultural Perspective', Learning and Socio-cultural Theory: Exploring Modern Vygotskian Perspectives International Workshop 2007, 1(1).

Heizmann H. (2009). „Knowledge Sharing through Communities of Practice: Exploring the 
cross Cultural Interface ee, In proceedings of International Conference on Organizational Learning, Knowledge and Capabilities (OLKC) - Amsterdam, the Netherlands

Hildreth, P. M. \& Kimble, C., (2004). 'Knowledge Networks: Innovation Through Communities of Practice', Idea Group Publishing, PA.

Hofstede, G. H. (2001). 'Culture's Consequences: Comparing Values, Behaviors, Institutions and Organizations across Nations', Sage Publications Thousand Oaks, CA.

Husted, K. \& Michailova, S. (2002). 'Diagnosing And Fighting Knowledge-Sharing Hostility', Organizational Dynamics, Vol. 31, No.1, pp60-73.

Johnson, C. M. (2001). 'A Survey of Current Research on Online Communities of Practice', The Internet and Higher Education, 4(1), Pp. 34

Kowch, E., \& Schwier, R. (1997). Considerations in the Construction of Technology-Based Virtual Learning Communities. Canadian Journal of Educational Communication, 26(1), $1-12$

Lantolf, P. James. (2002). Introducing Sociocultural Theory, Oxford University Press

Lave, J. \& Wenger, E., (1991). Situated Learning: Legitimate Peripheral Participation, Cambridge University Press, Cambridge, UK.

Leary, G. P. \& Fontainha, E. (2007). 'Communities of Practice and Virtual Learning Communities: Benefits, Barriers and Success Factors’, eLearning Papers, Issue No. 5

Li, W., Downey, S. \& Wentling, T. (2008). 'Online Knowledge Sharing in a Multinational Corporation: Chinese versus American Practices', Proceedings of the American Society for Information Science and Technology, (44) 1, p. 1-13

Marton, F., \& Booth, S. (1997). Learning and Awareness, Hillsdale, NJ: Lawrence Erlbaum

McCalla, G. (2000). 'The Fragmentation of Culture, Learning, Teaching and Technology: Implications for the Artificial Intelligence in Education Research Agenda in 2010', International Journal of Artificial Intelligence in Education, 11(2), 177-196

McLellan, H. (1995). 'Situated Learning Perspectives', Englewood Cliffs, NJ: Educational Technology Publications

Nonaka, I. (1994). 'A Dynamic Theory of Organizational Knowledge Creation', Organization Science 5 (1), 14-37

Nonaka, I. \& Takeuchi, H., (1995). 'The Knowledge-Creating Company: How Japanese 
Companies Create the Dynamics of Innovation', Oxford University Press, New York, USA

Pang, M. (1999). 'Two Faces of Variation: On Continuity in the Phenomenographic Movement', Paper presented at the 8th Biennial Conference of the European Association for Research in Learning and Instruction, Goteborg

Romm, C.T., Pliskin, N., Clarke, R.J. (1997). 'Virtual Communities And Society: Toward An Integrative Three-Phase Model', International Journal of Information Management. Vol. 17 No.4, pp.261-70

Ryan, G.W. \& Bernard, H.R. (2003). 'Techniques to Identify Themes', Field Methods, 15(1), 85-109

Selznick, P. (1996). In search of community. In Jackson, W. and Vitek, W. (Eds.) Rooted in the land: Essays on community and place, (pp. 195-203). New Haven: Yale University Press.

Schwier, R.A. (2007). 'A Typology Of Catalysts, Emphases And Elements Of Virtual Learning Communities', In R. Luppicini (Eds.), Trends in distance education: A focus on communities of learning (pp. 17-40). Greenwich, CT: Information Age Publishing

Svensson, L. (1997). 'Theoretical Foundations of Phenomenography', Higher Education Research \& Development, 16(2), 159-171

Thorne, S. (1999). 'Educational and Foreign/Second Language Uses Of Computer-Mediation: A Review of Research. In: An Activity Theoretical Analysis Of Foreign Language Electronic Discourse (Eds.), University of California, Berkeley

Von Wartburg, I., Rost, K., \& Teichert, T. (2006). 'The Creation Of Social And Intellectual Capital In Virtual Communities Of Practice: Shaping Social Structure In Virtual Communities Of Practice', International Journal of Learning and Change, 1(3), 299-316.

Vygotsky, L.S. (1978). 'Mind in Society: The Development of Higher Psychological Processes', Cambridge, MA: Harvard University Press

Webb, G. (1997). Deconstructing Deep and Surface: Towards a Critique of Phenomenography, Higher Education, Vol. 33, p. 195-212

Wenger, E. (1998). Communities of Practice: Learning, Meaning, and Identity. Cambridge: Cambridge University Press

Wenger, E., McDermott, R. \& Snyder, W. (2002). 'Cultivating Communities of Practice: A Guide to Managing Knowledge, Harvard Business School Press Boston, MA 


\section{Macrothink

White, I.K. \& Pagano, R (2007). 'Making It Stick: The use of Online Discussion Fora to Support Continuing Professional Development in Higher Education Communities of Practice. Proceedings of the 2nd International Conference on e-Learning, New York, 28-29 